УДК 316.75:316.642.3

DOI: $10.32837 / 2519-8858 / 10 / 132$

Наталья Стеркул

канд. полит. наук, доцент, департамент международных отношений

Молдавский Государственный Университет, г. Кишинев, Республика Молдова

\title{
РЕАЛИЗАЦИЯ СОГЛАШЕНИЯ ОБ АССОЦИАЦИИ РЕСПУБЛИКИ МОЛДОВА И ЕС: СЛОЖНОСТИ ПОЛИТИЧЕСКОЙ МОДЕРНИЗАЦИИ И РЕФОРМ
}

Аннотация. Анализируются основные сложности политической модернизации и реформ в контексте реализации Соглашения об ассоциации Республики Молдова и Европейским Союзом. После подписания в 2014 году Соглашения об ассоциации с EC, Республика Молдова сосредоточила усилия на политической модернизации и внутренних реформах. Был принят Национальный план действий по внедрению данного документа на 2017- 2019 годы. Несмотря на то, что Европейская Комиссия в своих докладах констатирует наметившееся продвижение в вопросах модернизации государства, автор обращает внимание на внутренний политический кризис, политическую и экономическую нестабильность, незрелость демократии и проблемы в сфере правосудия. Реформы, предусмотренные Соглашением об ассоциации, требуют развития политических институтов, соблюдения верховенства права, повышения уровня экономического развития, а также культурного и научного потенциала. ЕС предоставляет финансовую и техническую помощь для реализации данного Соглашения. Республике Молдова предстоит приложить усилия для того, чтобы завершить реформы в области внешней политики и безопасности, сфере правосудия и экономического сотрудничества и выйти на новый уровень развития.

Соглашение об ассоциации Республики Молдова и ЕС предусматривает взаимодействие власти и гражданского общества. То есть, его успех зависит не только от действий властных структур, но и от активного участия институтов гражданского общества. Политическая модернизация и реформы будучи взаимосвязанными категориями предполагают использование инновационного инструментария и выработки эффективных механизмов внедрения современных практик, направленных на развитие политических институтов. Это потребует времени и включенности всего населения в процессы реформирования государства и выхода страны на новый уровень развития. В этой связи важным видится предложить следующие рекомендации: повышать уровень доверия населения к властям, правоохранительным органам и работникам государственных структур; - формировать культуру правосознания в обществе и усилить антикоррупционные меры; - сосредоточить усилия на выгодах от реализации Соглашения об ассоциации с ЕС, которые должны отражаться не только в статистических данных, но и быть ощутимыми для рядовых граждан.

Ключевые слова: Соглашение об ассоциации, политическая модернизация, реформы, политические институты, демократия, правосудие, гражданское общество.

Подписав в 2014 году Соглашение об ассоциации с Европейским Союзом, Республика Молдова взяла на себя ряд определенных обязательств по проведению реформ и преобразований для глубинной модернизации государства. Получая значительную финансовую и техническую помощь со стороны ЕС, властные структуры государства сумели инициировать процессы внедрения европейских стандартов. Однако, ускорить эти процессы пока не удается в силу сложившейся внутриполитической ситуации и затяжного кризиса в котором оказалась страна.

Проблема данного исследования обосновывается важностью изучения и анализа реализации Соглашения об ассоциации Республики Молдова и Европейского Союза. Несмотря на определенные достижения в этой области, сложности политической модернизации и внедрения реформ, соответствующих европейским стандартам и нормам, ЕС становятся все более ощутимыми и требуют комплексного рассмотрения с целью выработки практических рекомендаций для их разрешения.

Проведенный анализ научных исследований позволяет заключить, что комплексного научного исследования на местном уровне по изучению реализации Соглашения об ассоциации Республики Молдова и ЕС не было проведено. Вместе с тем, 
предусмотренная в рамках указанного документа модернизация государства и реализация намеченных реформ требует детального анализа. В рамках данной работы, мы опирались на официальные документы и доклады ЕС, а также на доклады по оценке прогресса и проблем в этом направлении, сделанные молдавскими аналитиками. Вместе с тем, следует отметить, что в научном сообществе Республики Молдова достаточно много работ, затрагивающих проблемы европейской интеграции, в которых обращается внимание на сложности проведения реформ и преобразований. Среди них следует выделить Г. Кэлдаре [7, с. 377386], Г. Ульян и М. Браду [6, с. 55-66], В. Сакович и Г. Рукснак [4, с. 146-165], Г. Василеску [10. с. 527-536], К. Морарь [9, с. 227-244]. Все они послужили существенным подспорьем для описания внутриполитической ситуации в Республике Молдова, в условиях которой власти предпринимают попытки осуществления реформ.

Целью данной статьи является выявление основных сложностей политической модернизации и реформ в Республике Молдова в процессе реализации Соглашения об ассоциации с ЕС.

Соглашение об ассоциации является одним из основополагающих структурных элементов, обеспечивающих правовую базу в диалоге Республики Молдова - Европейский Союз, предусматривающий свод положений, направленных на реформирование государства, реализация которых позволит вывести страну на новый уровень развития. Модернизация и реформы предполагают качественное развитие политических институтов, правовой системы и судебных инстанций, экономического и банковского секторов, повышения уровня научнокультурного потенциала. Для реализации этого, в 2014 году на местном уровне Правительством Республики Молдова был разработан Национальный План Действий для имплементации Соглашения об ассоциации [3].

Следует отметить, что подавляющее большинство действий, которые были реализованы в 2014-2016гг. носят законодательный, нормативный характер. Это предполагает, что практические результаты такого рода мер потребуют времени, они не могут быть ощутимы в одночасье. Некоторые позитивные изменения отмечаются в области политических реформ, прав человека, правосудия и выработки антикоррупционных. Попытаемся разобраться с происходящими преобразованиями и выявить основные сложности практической реализации реформ.

Ожидалось, что процесс преобразований будет происходить планомерно. ЕС приложил немало усилий для интенсификации диалога по вопросам реформ. Регулярные консультации, рекомендации Венецианской Комиссии, финансовая помощь все это стало регулярной основой взаимодействия Европейского союза с Республикой Молдова. Отношения данных субъектов в период 2014-2016 гг. были чрезвычайно активны. С большой долей вероятности можно предположить, что их можно было бы назвать весьма плодотворными [8. с. 2-3]. Достижения Республики Молдова за 2014 год в рамках Восточного партнерства были признаны одними из самых успешных среди стран-участниц. Однако определенная череда событий во внутренней политике страны негативно отразилась на диалоге РМ-ЕС. В частности, речь идет о политической и экономической нестабильности, явившимися результатом нашумевшей кражи миллиарда из банковской системы страны. Коррупция в высших эшелонах власти и крайне медленное расследование обстоятельства данного дела, привели к тому, что в 2015 году Европейский союз приостановил финансовую помощь Республике Молдова. Кроме того, разочарованность населения действиями политической элиты, поддерживаемых европейскими партнерами, в значительной степени снизило популярность европейского вектора в Республике Молдова.

Однако, проевропейскому большинству удалось сохранить внешнеполитический вектор развития. В 2016 году власти страны декларировали реализацию Соглашения об ассоциации с ЕС одним из ключевых приоритетов и усилили работу над реформированием страны. Одними из основополагающих задач стали: политический диалог и реформы в области внешней политики и безопасности; правосудие, свобода и безопасность; экономическое сотрудничество.

(C) Н. Стеркул, 2019 
Тем самым европейская интеграция была продолжена посредством активизации функционирования определенных рычагов, политико-правовых инструментов и методов, способствующих сближению с ЕС. В конце 2016 года Правительство РМ издает Постановление «Об утверждении Национального плана действий по внедрению Соглашения об ассоциации Республика Молдова - Европейский Союз на 2017-2019 годы» [2]. Согласно данному документу Министерства и другие органы публичной власти обязуются реализовывать меры, включенные в указанный план, предоставлять ежеквартальные отчеты об их выполнении, а также апеллировать статистическими данными, необходимым для разработки показателей воздействия с целью отражения выгод от реализации Соглашения об ассоциации Республика Молдова - ЕС. Контроль за выполнением Постановления был возложен на Министерство иностранных дел и европейской интеграции.

В результате, в конце 2016 года финансовая помощь со стороны европейских структур была возобновлена. Международный Валютный Фонд выделил 178 млн. долл. на трехлетний период для продолжения процесса политической модернизации и завершения начатых реформ.

В 2017 году Европейская Комиссия опубликовала свой первый доклад о реализации данного документа, который констатировал, что Республика Молдова инициировала проведение намеченных реформ, однако требуются в этом направлении дополнительные усилия, в частности в вопросах, касающихся демократии, правового государства и деловой среды. Несмотря на констатацию европейскими партнерами наметившегося продвижения во внутренних преобразованиях, многие деструктивные тенденции продолжают сохраняться. Однако, понимание необходимости радикальных трансформаций и выхода страны из затянувшегося кризиса становилось все более глубоко осознанным среди всего населения.

Необходимым видится отметить, важность самой идеологии модернизации, особенно для властных структур, которые должны в еще большей степени сосредоточить свои действия на налаживании постоянного, непрерывного диалога с населением. Это позволит выработать наиболее эффективные социальные инструменты реализации намеченных преобразований, поскольку ни одна стратегия не сможет быть успешно реализована, если в ее осуществлении не будут участвовать основные слои населения. В нынешних условиях процесс модернизации осуществляется нарастающим потоком технологических и социокультурных инноваций, создаваемых обществом [4, с. 147]. Ввиду этого интересы и ценности молдавского общества должны оставаться приоритетными. В общем плане политическая модернизация означает формирование и развитие политических институтов, которые окажутся способными улучшить позиционирование государства в международных экономических и политических отношениях.

Реформы подразумевают преобразование, изменение какой-либо существенной стороны жизни общества при сохранении основ его экономического и государственного строя. Реформа призвана повысить общественное доверие к органам государственной власти, создать профессиональную среду, способную конкурировать с частным сектором и привлекать опытных и талантливых специалистов и руководителей. В случае Республики Молдова, для этого важно не только повышать уровень демократии в стране, но и проводить целый комплекс антикризисных и антикоррупционных мероприятий, которые позволили бы разрешить существующие проблемы.

Вполне обоснованным видится обратить внимание на структуру Соглашения об ассоциации. После раздела I данного документа, в котором кратко излагаются общие положения, следует раздел о политическом диалоге и реформе, сотрудничестве в области внешней политики и политики безопасности. В нем прописаны цели политического диалога и обстоятельно изложено содержание внутренней реформы. Она предполагает сотрудничество сторон в сфере развития, укрепления стабильности и эффективности демократических институтов, судебных инстанций, правоохранительных органов, соблюдения прав человека, реформу публичной администрации и создание прозрачного, профессионального государственного аппарата [5].

(C) Н. Стеркул, 2019 
Важность повышения уровня компетентности политической элиты представляет особую значимость для Республики Молдова, отчасти в этом состоит национальный интерес государства. Управленческие тренды, которыми руководствовались властные структуры в проведении внутренней и внешней политики после 2014 года, оказались малоэффективны. Разобщенность действий властных структур, чрезмерное использование административных ресурсов в собственных политических интересах, сложности организации эффективной политической системы породили негативное восприятия складывающегося положения дел во внутренней политике страны. У значительной части населения сложилось мнение о декларативном характере модернизационных преобразований и реформ ввиду того, что результаты их практической реализации фактически отсутствуют.

Несмотря на сотрудничество с европейскими партнерами, неоднократные обращения молдавских властей за политическими консультациями и финансовой помощью, все же важнейшие вопросы во внутренней политике страны принимаются исключительно из собственного видения внутриполитического сценария последующего развития событий. Это отчетливо можно было проследить в условиях перехода Республики Молдова к смешанной избирательной системе. Невзирая на критику со стороны ЕС, выражение опасений, к которым могут привести радикальные изменения в электоральных процессах данный шаг в сложившейся кризисной ситуации, власти страны не смогли отойти от намеченных планов.

Проводя анализ программ политических партий и высказываний представителей политической элиты, можно проследить, что многие положения в них связаны отчетливым влиянием внешнеполитического вектора, которые обуславливают основной посыл необходимости консолидации усилий населения. Это должно найти выражение в выработке единства, общности позиции и сплоченности масс. В свою очередь высказывания представителей европейских структур также являются достаточно весомыми в формировании общественного мнения, касающегося проведения внутренних преобразований [9, с. 228]. Проведенная работа в этом направлении принесла свои результаты. Для достижения большего эффекта важным видится отойти от разобщенности действий властных структур и прийти к консолидации усилий, направленных на продолжение реализации европейской интеграции и проведения реформ.

В определенной степени именно Соглашение об ассоциации подтолкнуло местные власти к реформированию сектора правосудия. Несмотря на то, что реформа была начата еще в 2010 году, основные достижения были сделаны в этой области после 2014 года. Следует обратить внимание, что Соглашение об ассоциации предусматривает вопросы, касающиеся правосудия, свободы и безопасности, в частности, положения о верховенстве права, независимости судебной системы, доступа к правосудию, права на судебное разбирательство и другие.

При поддержке ЕС в данной области произошли важные изменения, однако, некоторые проблемы продолжают сохраняться и требуют значительных усилий для их решения. В настоящее время предстоит решить вопросы, касающиеся пересмотра роли Высшей судебной палаты с целью отхода от чрезмерной концентрации полномочий в этом органе. Не менее важной является проблема превентивных арестов и большего количества приговоров, вынесенных по уголовным делам. Ввиду этого, судебные слушания сделают открытыми. Пристального внимания требует и реформа кадров в судебном секторе и обеспечение прозрачности, в том числе в вопросах назначения судей.

$\mathrm{He}$ решенным остается вопрос о повышении доверия среди граждан к правоохранительным органам и государственным служащим. Несмотря на борьбу с коррупцией, количество правонарушений в этой области не снижается. В 2018 году по стране прокатилась очередная волна скандалов, связанная с коррупцией среди правоохранительных органов, образовательных и медицинских учреждений. Это подтверждает тот факт, что достичь высокого уровня правосознания в обществе, правовой культуры и первостепенности соблюдения «буквы закона» пока не удается. 
Важным видится участие населения, гражданского общества в целом и молодежи в частности в процессе реформирования государства. В данном контексте важным видится отметить, что гражданское общество за последние годы существенно укрепилось. Регистрация некоммерческих организаций упрощена и носит уведомительный характер. Отчеты об их деятельности в обязательном порядке публикуются в СМИ или размещаются на специализированных сайтах в Интернете. Участие неправительственных организаций в различных зарубежных проектах стало привычным делом, равно как и финансирование данных проектов из зарубежных фондов. Однако, добиться в Республике Молдова какихлибо радикальных изменений с помощью гражданской активности фактически невозможно, т.е., по сути, отсутствует предпосылка для мотивации гражданской активности.

Подготовка подрастающего поколения к участию в политических и избирательных процессах, социальной политике в этом контексте играет особую роль. Должны быть использованы все возможности для упрочения роли молодежи в процессе модернизации Республики Молдова.

Несмотря на то, что были запущены важные реформы в публичном секторе в целях ускорения экономического роста, укрепления государственной службы и продвижения социальных прав, положение молодежи, особенно в сельской местности фактически не изменилось. Молодежь представляет собой социальную группу, которая очень чувствительна к политическим, экономическим и социальным изменениям страны. Эта группа населения со своими потребностями, проблемами, мнениями и ценностями представляет собой чрезвычайно важную категорию, значительно вовлеченную как во внутреннюю, так и во внешнюю миграцию [1].

Соглашение об ассоциации с ЕС предусматривает вопросы, касающиеся молодежной политики, содействие участию молодых людей в обществе, стимулирование активной гражданской позиции [5]. На сегодняшний день в этой области выделяются следующие проблемы:

- Низкий уровень вовлеченности и участия молодежи, категория пассивных молодых людей находится под угрозой несостоятельности на рынке труда, безработицы, социальной изоляции и миграции;

- Неравный доступ к возможностям, указывающий на фактор дискриминации молодых людей, вызванный коррумпированным обществом, низким доступом к социальным услугам, безденежьем;

- Информированность молодежи - ключевая предпосылка для обеспечения доступа к социальным и гражданским возможностям [1].

Выделенные проблемы усугубляются ввиду нестабильной экономической ситуации; неэффективности государственной политики в этой области; роста миграции молодых людей; недостаточных институциональных и финансовых возможностях в молодежном секторе.

Все это требует повышенного внимания руководства страны, выработки комплексной и эффективной стратегии действий, которая окажется способной кардинально изменить ситуацию и добиться активности гражданского общества. Участие молодежи в модернизационных процессах носит объективный, закономерный характер, подкрепленный заинтересованностью молодежи в этом процессе, поскольку тем самым эта группа населения обеспечивает себе гарантированное благополучие в будущем.

\section{Выводы и рекомендации}

Таким образом, Соглашение об ассоциации Республики Молдова и ЕС требует не только усилий властных структур, но и активное включение гражданского общества в процессы внутренних преобразований. Политическая модернизация и реформы будучи взаимосвязанными категориями предполагают использование инновационного инструментария и выработки эффективных механизмов внедрения современных практик, направленных на развитие политических институтов, правовой, экономической и социальной областей. Это потребует времени и включенности всего населения в процессы 
реформирования государства и выхода страны на новый уровень развития. В этой связи важным видится предложить следующие рекомендации:

- повышать уровень доверия населения к властям, правоохранительным органам и работникам государственных структур;

- формировать культуру правосознания в обществе и усилить антикоррупционные меры;

- сосредоточить усилия на выгодах от реализации Соглашения об ассоциации с ЕС, которые должны отражаться не только в статистических данных, но и быть ощутимыми для рядовых граждан.

\section{СПИСОК ВИКОРИСТАНИХ ДЖЕРЕЛ}

1. Национальная стратегия развития молодежного сектора - 2020 /I lex.justice.md/UserFiles/File/2014/mo293-296ru/strategie_166.doc

2. $\quad$ Постановление №1472 от 30.12.2016 «Об утверждении Национального плана действий по внедрению Соглашения об Ассоциации Республика Молдова - Европейский Сою3 на 2017-2019 годы»

http://lex.justice.md/viewdoc.php?action=view\&view=doc\&id=369730\&lang $=2$

3. Постановление Правительства Республики Молдова № 808 от 07.10. 2014 «об утверждении Национального плана действий по внедрению Соглашения об ассоциации Республики Молдова - Европейский Союз на период 2014-2016 годы» // http://lex.justice.md/viewdoc.php?action=view\&view=doc\&id=354939\&lang=2

4. Сакович В., Руснак Г. Экономическая безопасность Республики Молдова: вызовы, угрозы, источники угроз; препятствия инновационному развитию // Moldoscopie (Probleme de analiza politica). - Chisinau: USM, USPEE, AMPS. 2016. №3 (LXXIV). - C. 146165.

5. Соглашение об ассоциации между Европейским Союзом и Европейским сообществом по атомной энергии и их государствами-членами, с одной стороны, и Республикой Молдова, с другой стороны // https://gov.md/europa/sites/default/files/_____.pdf

6. Ульян Г., Браду М. Экономические отношения между Молдовой и Европейским Союзом / Детерминанты и перспективы политики европейской интеграции Республики Молдова. - Краков: Societas, 2015. - С. 55-66.

7. Căldare Gh. Probleme şi priorităţi în colaborarea Republicii Moldova cu Uniunea Europeană la etapa actuală. În: Ştiinţa politică şi societatea în schimbare: Mat. Conf. Şt. Int. dedicate celei de-a 20-a aniversări a Facultăţii Relaţii Internaţionale, Ştiinţe Politice şi Administrative, 13 noiemb. 2015. Chişinău: CEP USM, 2015, p. 377-386.

8. Groza I. ş.a. Raport alternativ de progres 2014-2016. Implementarea Acordului de Asociere Republica Moldova-Uniunea Europeană. Chişinău: IPRE, 2017. 67 p.

9. Morari C., Vasilescu Gr. Integrarea europeană. În: Relaţiile internaţionale în curriculumul universitar: bazele teoretico-metodologice. Chişinău: CEP USM, 2016, p. 227-244.

10. Vasilescu Gr. Despre extinderea geopolitică a Uniunii Europene. În: Ştiinţa politică şi societatea în schimbare: Mat. Conf. Şt. Internaţ. dedicate celei de-a 20-a aniversări a Facultăţii Relaţii Internaţionale, Ştiinţe Politice şi Administrative, 13 noiemb. 2015. Chişinău: CEP USM, 2015, p. 527-536.

\section{IMPLEMENTATION OF THE ASSOCIATION AGREEMENT BETWEEN THE REPUBLIC OF MOLDOVA AND EU: THE COMPLEXITIES OF POLITICAL MODERNIZATION AND REFORMS}


Summary. The main difficulties of political modernization and reforms in the context of implementation of the Association Agreement between the Republic of Moldova and the European Union are analyzed. Following the signing of the Association Agreement with the EU in 2014, Moldova has focused efforts on political modernization and internal reforms. A national action plan for the implementation of this document for 2017-2019 was approved. Although the European Commission notes in its reports that progress has been made in modernizing the State, the author draws attention to the internal political crisis, political and economic instability, immature democracy and problems in the justice sector. The reforms provided for in the Association Agreement require the development of political institutions, respect for the rule of law, improved economic development and cultural and scientific potential. The EU provides financial and technical assistance for the implementation of this Agreement. Moldova will have to make efforts to complete the reforms in the foreign and security policy, justice and economic cooperation and reach a new level of development. The Moldova-EU Association Agreement provides for the interaction between the authorities and civil society. That is, its success depends not only on the actions of the authorities, but also on the active participation of the civil society institutions. Political modernization and reforms, being interrelated categories, presuppose the use of innovative tools and elaboration of efficient mechanisms for the implementation of modern practices aimed at the development of political institutions. This will require time and the involvement of the entire population in the processes of reforming the state and bringing the country to a new level of development. In this regard, it would be important to propose the following recommendations: - to increase the level of public trust in the authorities, law enforcement bodies and employees of state structures; - to form a culture of legal consciousness in society and strengthen anticorruption measures; - to focus efforts on the benefits of the Association Agreement with the EU, which should be reflected not only in statistical data, but also be tangible for ordinary citizens.

Keywords: Association Agreement, political modernization, reforms, political institutes, democracy, justice, civil society. 